\title{
MONTH OF THE YEAR EFFECT PADA BEBERAPA PASAR MODAL DI ASIA TENGGARA DAN PASAR KOMODITAS
}

\author{
Robiyanto \\ Program Doktor Ilmu Ekonomi, Universitas Diponegoro \\ robiyanto76@gmail.com
}

\begin{abstract}
One of prominent phenomenon in capital market is month of the year effect which is the occurence of certain monthly pattern in capital market return during trading years. There were enormous researches, which had been done to explain this phenomenon in capital market but the results always varied. Unfortunately there was a few research to explain this phenomenon in commodities market. Based on these facts, research about this seasonality still need to be done both in capital market and commodities market. Data used in this study were several South East Asia monthly closing stock market indexes and several commodity product monthly closing prices such as gold, silver, platinum, paladium and West Texas Intermediate Crude Oil during January 1999 - March 2014 period. GARCH (1,1) was employed to analyze the data. The finding shows that month of the year effect still exist in capital market in South East Asia and commodity market during research period with various occurences. Each capital market and commodity market behaves variously during trading year. This may lead to an opportunity, which can be grabbed by active market switching strategy for sophisticated investors, and investors who have multiple access to regional capital markets and commodity markets.
\end{abstract}

Keywords: month of the year effect, calendar anomalies, commodity market, capital market

\section{PENDAHULUAN}

Efisiensi pasar modal merupakan topik yang sangat menarik bagi banyak peneliti (Boudreaux 1995). Efisiensi pasar modal ini menjadi objek penelitian yang berkembang pesat semenjak Fama $(1965,1970)$ memperkenalkan analisis teoretis mengenai efisiensi pasar dan mengembangkannya menjadi keuangan keperilakuan (Fama 1998). Salah satu bidang kajian terkait topik tersebut adalah mengenai keacakan (randomness) pergerakan harga saham maupun aset-aset keuangan lainnya guna membuktikan efisiensi pasar modal. Namun banyak dari temuan-temuan dalam penelitian empiris yang dilakukan menghasilkan kesimpulan bahwa terdapat adanya suatu pola tertentu pada return saham, misalnya penelitian Lakonishok dan Maberly (1990); Sias dan Starks (1995); Pearce (1996); Kamath et al. (1998); Brockman dan 
Michayluk (1998); Wang dan Walker (2000); Silva (2010); Swami (2012); Nawaz dan Mirza (2012) yang menemukan bahwa terdapat adanya pola harian pada return saham yang sering disebut dengan day of the week effect dan penelitian Boudreaux (1995); Giovanis (2009); Marrett dan Worthington (2011); Georgantopoulos et al. (2011); Swami (2012); Debasish (2012); Chia dan Liew (2012) yang menemukan adanya pola bulanan pada return saham yang disebut dengan month of the year effect.

Penelitian mengenai fenomena musiman (seasonality) ini juga menarik perhatian peneliti untuk mengkajinya pada pasar komoditas, misalnya Olowe (2010) yang meneliti fenomena ini di pasar komoditas untuk produk minyak mentah Laut Utara (Brent North Sea crude oil) yang merupakan minyak mentah acuan di Eropa. Penelitian tersebut menemukan bahwa ternyata pola-pola return ini tidak hanya terjadi pada di produk Brent North Sea crude oil, namun terdapat pola volatilitas yang mengindikasikan adanya month of the year effect pada volatilitas produk Brent North Sea crude oil. Hal ini tentu menimbulkan perspektif baru mengenai penelitianpenelitian tentang seasonality ini, terutama dari segi month of the year effect pada pasar modal secara umum dan pasar komoditas pada khususnya. Oleh sebab itu penelitian ini akan melakukan kajian mengenai month of the year effect pada beberapa pasar modal (dalam penelitian ini adalah pasar modal di Asia Tenggara) dan pada pasar komoditas untuk produk West Texas intermediate crude oil yang merupakan minyak acuan di dunia secara umum dan Amerika Serikat pada khususnya, dan produk logam mulia seperti emas, perak dan platinum serta produk logam industri seperti paladium.

Penelitian mengenai seasonalities atau yang juga disebut sebagai anomali pasar terutama month of the year effect seringkali dilakukan pada pasar modal saja. Penelitian serupa masih jarang ditemukan pada pasar komoditas. Sementara itu temuan penelitian mengenai month of the year effect ini masih cenderung berbedabeda satu sama lain. Oleh sebab itu penelitian mengenai month of the year effect pada pasar modal yang lain dan pasar komoditas masih menarik untuk dilakukan.

Hasil penelitian ini dapat memberikan kontribusi ilmiah pada bidang kajian anomali di pasar modal terutama yang berkaitan dengan month of the year effect dan menambah ragam temuan mengenai hal ini pada pasar komoditas. Hasil penelitian ini juga diharapkan dapat menambah wawasan para pelaku di pasar modal dan pasar komoditas terkait dengan adanya pola musiman yang dapat dimanfaatkan guna memaksimalkan kinerja portofolionya.

\section{KAJIAN PUSTAKA DAN PENGEMBANGAN HIPOTESIS}

Fama (1965) mendefinisikan pasar efisien sebagai pasar dimana terdapat sejumlah besar pihak yang berupaya untuk memaksimalkan laba secara rasional yang secara aktif bersaing satu sama lain untuk memprediksi nilai pasar suatu surat 
berharga di masa yang akan datang dan dimana hampir semua informasi penting terkini tersedia bebas bagi seluruh pelaku pasar. Lebih lanjut Fama (1965) menyatakan bahwa pasar yang efisien akan mengarah kepada situasi dimana harga saham aktual mencerminkan pengaruh dari informasi kejadian yang telah terjadi dan kejadian yang akan terjadi di masa mendatang yang diharapkan. Pada pasar modal yang efisien, harga saham aktual akan menjadi prediktor nilai intrinsik yang baik pada suatu waktu. Konsep ini kemudian dipertajam kembali oleh Fama (1970) dengan menyatakan bahwa pasar dengan harga saham yang selalu mencerminkan sepenuhnya informasi yang tersedia disebut dengan pasar modal yang efisien. Lebih lanjut dinyatakan pula bahwa terdapat tiga bentuk pengujian efisien pasar modal. Pengujian efisiensi bentuk lemah dimana pasar modal dinyatakan efisien jika pergerakan harga sahamnya adalah acak (random walk). Pengujian efisiensi bentuk setengah kuat dimana pasar modal dinyatakan efisien jika harga saham mencerminkan semua informasi yang tersedia secara publik. Pengujian efiensi bentuk kuat dimana pasar modal dinyatakan efisien jika harga saham mencerminkan semua informasi yang ada.

Pada pasar modal yang efisien dalam bentuk lemah, harga saham akan mengikuti pola acak dan tidak dapat diprediksi, namun berbagai bukti empiris menunjukkan bahwa ternyata pergerakan harga saham ini cenderung tidak acak bahkan membentuk suatu pola yang seringkali disebut dengan pola musiman (seasonality) atau calendar anomalies. Schwert (2002) mengemukakan bahwa calendar anomalies adalah bukti empiris yang tidak konsisten dengan teori perilaku penilaian aset. Salah satu calendar anomalies yang mengemuka adalah month of the year effect yaitu adanya pola pada bulan-bulan tertentu dalam setiap tahun.

Boudreaux (1995) melakukan kajian perilaku musiman month of the year effect pada indeks saham yang tercatat dalam Morgan Stanley Capital International Perspective (CIP) yang merupakan indeks untuk mengukur pasar modal global. Periode penelitian yang digunakan adalah dari Maret 1978 hingga Desember 1992, dengan menggunakan uji t berpasangan dan regresi OLS. Hasil penelitian ini menemukan adanya pola return yang positif secara bulanan untuk pasar modal di Denmark, Jerman dan Norwegia. Sedangkan pola return negatif ditemukan pada pasar modal Singapura dan Malaysia. Fatta-Bahadur dan Joshi (2005) melakukan kajian mengenai month of the year effect pada Nepal Stock Exchange Index periode Februari 1995 hingga Desember 2004. Analisis dilakukan dengan menggunakan regresi dengan variabel dummy. Hasil penelitian ini adalah bahwa tidak terdapat month of the year effect pada Nepal Stock Exchange Index.

Giovanis (2009) melakukan kajian mengenai month of the year effect secara lebih luas lagi dengan menggunakan 55 pasar modal dari 51 negara sebagai objek penelitiannya. Dengan menggunakan GARCH diperoleh hasil bahwa terdapat 20 pasar modal yang membukukan return pada bulan-bulan tertentu. Giovanis (2009) juga menemukan adanya February effect pada 9 pasar modal, January effect pada 7 
pasar modal, dan April effect pada 6 pasar modal yang diteliti. Pada bulan-bulan ini ditemukan return yang tertinggi dibandingkan bulan-bulan sebelumnya. Hasil yang berbeda ditemukan oleh Marrett and Worthington (2011) yang melakukan penelitian dengan menggunakan indeks-indeks harga saham yang ada di Australia Stock Exchange termasuk indeks harga saham sektoral. Dengan menggunakan analisis regresi, mereka menemukan bahwa terdapat month of the year effect di Australia Stock Exchange. Secara umum ditemukan bahwa return pada bulan April, Juli dan Desember lebih tinggi secara signifikan apabila dibandingkan bulan-bulan lainnya. Sedangkan pada saham-saham dengan kapitalisasi yang kecil ditemukan bahwa return bulan Januari, Agustus dan Desember lebih tinggi dibandingkan bulan lainnya.

Georgantopoulos et al. (2011) melakukan kajian mengenai calendar anomalies untuk pasar modal di kawasan Balkan seperti Romania, Bulgaria, Kroatia, Turki dan Yunani. Dengan menggunakan GARCH diperoleh hasil bahwa terdapat month of the year effect pada pasar modal Yunani dan Turki. Namun tidak ditemukan adanya month of the year effect pada pasar modal kawasan Balkan yang masih dalam tahap berkembang seperti Romania, Bulgaria dan Kroasia. Sementara itu Debasish (2012) mengkaji mengenai month of the year effect pada saham-saham sektor gas, minyak dan penyulingan yang tercatat di pasar modal India. Dengan menggunakan data periode Januari 2006 hingga Desember 2010 yang diolah dengan analisis regresi, diperoleh hasil bahwa terdapat month of the year effect pada saham-saham sektor gas, minyak dan penyulingan yang tercatat di pasar modal India. Secara umum return positif yang signifikan terjadi pada bulan September, Agustus dan Februari.

Chia and Liew (2012) meneliti mengenai month of the year effect pada indeks Nikkei 225 selama periode Januari 2009 hingga Juni 2009, dengan menggunakan analisis TGARCH. Temuan penelitian ini menunjukkan bahwa terdapat month of the year effect pada Tokyo Stock Exchange, dan bulan November merupakan bulan yang memiliki return tertinggi.

Hasil penelitian yang telah dilakukan tersebut cenderung beragam satu sama lain, dimana sangat ditentukan oleh kondisi dari masing-masing pasar yang diteliti. Hasil berbeda juga berpotensi ditemukan pada pasar komoditas. Oleh sebab itu penelitian mengenai month of the year effect pada pasar modal yang lain dan pasar komoditas masih menarik untuk dilakukan.

\section{Hipotesis}

Marrett dan Worthington (2011) mengemukakan bahwa tema yang konsisten dalam kajian efisiensi pasar modal adalah terkait adanya calendar anomalies atau pola musiman dalam return pasar saham. Temuan yang mengemuka dalam bidang ini adalah adanya return pada suatu masa (bulan) yang lebih tinggi dibandingkan bulan lainnya. Apabila ditemukan adannya pola pada return pasar ini, maka dapat disimpulkan bahwa pasar modal tidaklah efisien dalam bentuk lemah. Berbagai 
penelitian yang telah dilakukan seperti penelitian Boudreaux (1995); Fatta-Bahadur dan Joshi (2005); Giovanis (2009); Marrett dan Worthington (2011); Georgantopoulos et al. (2011); Debasish (2012); Chia dan Liew (2012) menemukan bahwa terdapat pola di dalam return saham dalam bulan-bulan perdagangan dalam satu tahun. Berdasarkan riset terdahulu dan argumentasi di atas maka dirumuskan hipotesis sebagai berikut.

H1: Terdapat month of the year effect pada pasar modal dan pasar komoditas

\section{METODA PENELITIAN}

\section{Data Penelitian}

Data yang dipergunakan dalam penelitian ini adalah adalah data penutupan bulanan pada pasar modal yang diteliti dan data penutupan bulan pada produk komoditas yang diteliti seperti emas, perak, platinum dan paladium serta minyak mentah West Texas intermediate selama periode Januari 1999 hingga Maret 2014. Data pasar modal yang dibutuhkan adalah data penutupan bulanan Indeks Harga Saham Gabungan (IHSG) di Bursa Efek Jakarta, data Strait Times Index (STI) di Singapore Stock Exchange, data KLSE Composite (KLSE) dari Kuala Lumpur Stock Exchange dan data indeks SET (SET) dari Stock Exchange Thailand. Data pasar modal ini ini diperoleh dari Statistik Pasar Modal yang diterbitkan oleh Otoritas Jasa Keuangan (dahulu Bapepam). Sedangkan data harga penutupan bulanan untuk pasar komoditas dalam penelitian ini ditujukan untuk produk emas, perak, platinum dan paladium serta minyak mentah West Texas Intermediate. Harga penutupan bulanan logam mulia (emas, perak dan platinum) dan logam industri (paladium) diperoleh dari Bloomberg dan www.kitco.com, sedangkan harga penutupan bulanan minyak mentah West Texas Intermediate (WTI) diperoleh dari U.S. Energy Information Administration.

\section{Teknik Analisis}

Analisis data dilakukan dengan menggunakan Generalized Autoregressive Conditional Heteroscedasticity (GARCH) $(1,1)$. Model GARCH dikembangkan oleh Bollerslev (1986) yang merupakan pengembangan dari model ARCH. Model ini dibangun untuk menghindari ordo yang terlalu tinggi pada model $A R C H$ dengan berdasar pada prinsip parsimoni atau memilih model yang sederhana, sehingga akan menjamin variansinya selalu positif.

Persamaan yang dipergunakan adalah sebagai berikut:

$$
\begin{aligned}
\mathrm{R}_{\text {Commodity }}= & \beta_{1} \mathrm{JAN}+\beta_{2} \mathrm{FEB}+\beta_{3} \mathrm{MAR}+\beta_{4} \mathrm{APR}+\beta_{5} \mathrm{MAY}+\beta_{6} \mathrm{JUN}+\beta_{7} \mathrm{JUL}+\beta_{8} \mathrm{AUG}+ \\
& \beta_{9} \mathrm{SEPT}+\beta_{10} \mathrm{OCT}+\beta_{11} \mathrm{NOV}+\beta_{12} \mathrm{DEC}+\varepsilon_{\mathrm{t}} \ldots \ldots \ldots \ldots \ldots \ldots \ldots \ldots \ldots \ldots \ldots \ldots \ldots \ldots \ldots \ldots
\end{aligned}
$$


dengan

$\varepsilon_{\mathrm{t}}=\Phi_{\mathrm{t}} \varepsilon_{\mathrm{t}-1}+\ldots+\Phi_{\mathrm{t}} \varepsilon_{\mathrm{t}-\mathrm{p}}+\eta_{\mathrm{t}}$

$\eta_{\mathrm{t}}=\sigma_{\mathrm{t}} \epsilon_{\mathrm{t}}$

$\sigma_{\mathrm{t}=\alpha_{0}}^{2}+\alpha_{1} \eta_{\mathrm{t}-1}^{2}+. .+\alpha_{\mathrm{p}} \eta_{\mathrm{t}-\mathrm{p}}^{2}+\beta_{1} \sigma_{\mathrm{t}-1}^{2}+\ldots+\beta_{\mathrm{q}} \sigma_{\mathrm{t}-\mathrm{q}}^{2}$

dimana $\epsilon_{\mathrm{t}}$ adalah independent and identical distributed $\mathrm{N}(0,1)$ dan tidak tergantung dari keadaan masa lalu dari $\eta_{\mathrm{t}-\mathrm{p}}$.

$\mathrm{R}_{\text {Commodity }}=$ Return komoditas (logam mulia seperti emas, perak, platinum dan paladium dan minyak mentah WTI) yang diteliti.

JAN $=$ Dummy variable bulan perdagangan, 1 jika bulan Januari dan 0 jika tidak.

FEB = Dummy variable bulan perdagangan, 1 jika bulan Februari dan 0 jika tidak.

MAR = Dummy variable bulan perdagangan, 1 jika bulan Maret dan 0 jika tidak.

APR $=$ Dummy variable bulan perdagangan, 1 jika bulan April dan 0 jika tidak.

MAY = Dummy variable bulan perdagangan, 1 jika bulan Mei dan 0 jika tidak.

JUN = Dummy variable bulan perdagangan, 1 jika bulan Juni dan 0 jika tidak.

JUL $\quad=$ Dummy variable bulan perdagangan, 1 jika bulan Juli dan 0 jika tidak.

AUG = Dummy variable bulan perdagangan, 1 jika bulan Agustus dan 0 jika tidak.

SEPT = Dummy variable bulan perdagangan, 1 jika bulan September dan 0 jika tidak.

OCT = Dummy variable bulan perdagangan, 1 jika bulan Oktober dan 0 jika tidak.

NOV = Dummy variable bulan perdagangan, 1 jika bulan November dan 0 jika tidak.

DEC = Dummy variable bulan perdagangan, 1 jika bulan Desember dan 0 jika tidak.

Sebelum dilakukan analisis $G A R C H$, dilakukan uji stasioneritas data dengan menggunakan Augmented Dickey-Fuller Test/ADF (Greene 2003; Enders 2009). Uji stasioneritas data ini dilakukan dengan menggunakan level, 1st difference dan 2nd difference (Enders 2009).

\section{HASIL DAN PEMBAHASAN}

\section{Hasil Uji Augmented Dickey Fuller}

Pada Tabel 1 dapat dilihat hasil pengujian Augmented Dickey Fuller. Berdasarkan Tabel 1, didapati bahwa nilai t statistik dari variabel yang diuji signifikan pada tingkat signifikansi 1 persen. Oleh sebab itu disimpulkan bahwa semua data yang dipergunakan dalam penelitian adalah stasioner. 
Tabel 1

Hasil Uji Augmented Dickey Fuller

\begin{tabular}{clcc}
\hline No. & Keterangan & t-Statistic & Prob. \\
\hline 1. & IHSG & $-10,74096$ & 0,0000 \\
2. & KLSE & $-13,05820$ & 0,0000 \\
3. & PSE & $-12,41782$ & 0,0000 \\
4. & SET & $-12,99593$ & 0,0000 \\
5. & STI & $-11,75087$ & 0,0000 \\
6. & Gold & $-15,17633$ & 0,0000 \\
7. & Silver & $-14,40454$ & 0,0000 \\
8. & Platinum & $-14,66503$ & 0,0000 \\
9. & Paladium & $-13,03860$ & 0,0000 \\
10. & WTI & $-10,82818$ & 0,0000 \\
\hline
\end{tabular}

Sumber: Statistik Pasar Modal, Bloomberg, kitco.com dan USEIA, diolah.

\section{Hasil Analisis GARCH (1,1)}

Hasil analisis GARCH $(1,1)$ dapat dilihat pada Tabel 2. Hasil pengujian (z statistic) dalam analisis GARCH $(1,1)$ menunjukkan bahwa terdapat nilai z statistic bulan-bulan perdagangan yang signifikan pada tingkat signifikansi 10 persen, 5 persen bahkan 1 persen. Oleh sebab itu disimpulkan untuk menerima H1 yang menyatakan bahwa terdapat month of the year effect pada pasar modal dan pasar komoditas.

Hasil analisis GARCH $(1,1)$ menunjukkan bahwa secara umum terdapat month of the year effect pada setiap pasar modal dan pasar komoditas yang diteliti. Hal ini ditandai dengan adanya bulan-bulan yang memiliki pengaruh yang signifikan terhadap return pasar saham dan return komoditas. Hampir semua pasar modal yang diteliti juga memiliki koefisien $A R C H$ yang signifikan kecuali SET dan paladium. Hal ini menunjukkan bahwa kesalahan prediksi pasar modal dan pasar komoditas yang diteliti dipengaruhi oleh residual kuadrat sebelumnya, kecuali untuk SET dan paladium. Lebih lanjut ditemukan pula bahwa sebagian pasar modal dan pasar komoditas yang diteliti juga memiliki koefisien $G A R C H$ yang signifikan kecuali IHSG, PSE, platinum dan paladium. Hal ini menunjukkan bahwa pasar saham dan pasar komoditas ini dipengaruhi pula oleh volatilitas masa lalunya.

Terdapat pola bulanan (month of the year effect) pada semua pasar modal dan pasar komoditas yang diteliti, namun pola bulanan setiap pasar modal dan pasar komoditas ini berbeda satu sama lain. Misalnya bulan Maret, April dan Desember memiliki pengaruh yang signifikan untuk IHSG dengan bulan April sebagai bulan dengan return positif tertinggi yang signifikan, disusul oleh bulan Desember dan Maret. Pasar modal Malaysia yang diwakili oleh indeks KLSE dipengaruhi secara positif signifikan oleh Oktober dan Desember, dengan return tertinggi yang signifikan di bulan Desember. 
Tabel 2

Hasil Analisis GARCH (1,1)

\begin{tabular}{|c|c|c|c|c|c|c|c|c|c|c|}
\hline Bulan & IHSG & KLSE & PSE & SET & STI & GOLD & SILVER & $\begin{array}{c}\text { PLATIN } \\
\text { UM }\end{array}$ & $\begin{array}{l}\text { PALAD } \\
\text { IUM }\end{array}$ & WTI \\
\hline JAN & 0.013 & -0.006 & $0.024^{*}$ & 0.002 & $0.019^{* *}$ & 0.003 & 0.0244 & $0.044^{* * *}$ & $0.058^{* * *}$ & 0.032 \\
\hline FEB & 0.003 & 0.008 & -0.006 & 0.030 & 0.004 & 0.016 & 0.009 & $0.035^{* *}$ & 0.012 & 0.018 \\
\hline$M A R$ & $0.028^{*}$ & 0.011 & 0.003 & 0.0003 & 0.014 & -0.014 & 0.002 & -0.008 & $0.032 *$ & $0.061^{* * *}$ \\
\hline$A P R$ & $0.055^{* * *}$ & 0.007 & 0.019 & 0.023 & 0.013 & 0.015 & -0.007 & -0.002 & -0.011 & 0.015 \\
\hline MAY & 0.004 & 0.011 & 0.005 & -0.0004 & $-0.018^{* *}$ & -0.0009 & 0.003 & 0.021 & -0.015 & 0.009 \\
\hline JUN & 0.014 & 0.010 & 0.003 & 0.009 & $0.020^{*}$ & 0.0011 & -0.016 & -0.014 & $-0.043^{*}$ & 0.013 \\
\hline$J U L$ & 0.023 & 0.012 & 0.012 & 0.010 & $0.034 * * *$ & -0.003 & 0.013 & 0.008 & 0.031 & 0.040 \\
\hline$A U G$ & -0.028 & -0.009 & -0.012 & 0.007 & -0.011 & $0.031 * * *$ & -0.007 & $0.026^{*}$ & 0.011 & 0.024 \\
\hline SEP & 0.019 & 0.006 & 0.009 & 0.011 & $0.021^{* *}$ & $0.040^{* * *}$ & $0.044^{* * *}$ & 0.007 & 0.006 & 0.003 \\
\hline OCT & 0.013 & $0.027^{* *}$ & -0.006 & 0.017 & 0.008 & -0.006 & -0.018 & 0.012 & 0.026 & -0.005 \\
\hline NOV & 0.013 & -0.004 & 0.009 & 0.006 & 0.011 & $0.024^{* *}$ & 0.008 & 0.023 & 0.001 & -0.001 \\
\hline$D E C$ & $0.054 * * *$ & $0.028 * * *$ & 0.024 & $0.029 *$ & $0.020^{*}$ & 0.002 & 0.011 & 0.014 & 0.029 & -0.004 \\
\hline $\begin{array}{c}\text { Resid(- } \\
1)^{\wedge} 2\end{array}$ & $0.242^{* *}$ & $-0.068 * *$ & $-0.074 * *$ & 0.016 & 0.268 & $0.328^{*}$ & $0.220 * *$ & $0.593^{* *}$ & 0.442 & $0.158^{*}$ \\
\hline GARCH & -0.093 & $1.023^{* * *}$ & -0.485 & $0.951^{* * *}$ & $0.757^{* * *}$ & $0.481^{* *}$ & $0.751^{* * *}$ & -0.004 & -0.018 & $0.593^{* *}$ \\
\hline
\end{tabular}

Sumber: Statistik Pasar Modal, Bloomberg, kitco.com dan USEIA, diolah

Keterangan:

*Signifikansi pada tingkat kepercayaan $10 \%$

**Signifikansi pada tingkat kepercayaan 5\%

***Signifikansi pada tingkat kepercayaan $1 \%$

Hal berbeda ditemukan pada pasar modal Filipina yang diwakili oleh indeks PSE. Pada pasar modal Filipina ditemukan bahwa terdapat January effect yang signifikan. Return di bulan Januari merupakan yang terbesar dibandingkan bulanbulan lainnya. Sedangkan pada pasar modal Thailand yang diwakili oleh indeks SET, return pada bulan Januari tidak berbeda dengan bulan-bulan lainnya, namun justru pada bulan Desember ditemukan return positif yang signifikan.

Terdapat banyak bulan-bulan yang memiliki pengaruh signifikan terhadap pasar modal Singapura yang diwakili oleh indeks STI. Sebanyak enam bulan perdagangan yaitu Januari, Mei, Juni, Juli, September dan Desember memiliki pengaruh yang signifikan terhadap return saham. Bulan Mei memiliki pengaruh negatif yang signifikan, sedangkan bulan Juli memiliki return positif terbesar yang signifikan.

Pada pasar komoditas juga ditemukan pola return bulanan yang berbeda satu dengan lainnya. Untuk pasar emas, ditemukan bahwa bulan September merupakan bulan yang menghasilkan return positif yang signifikan tertinggi, disusul bulan Agustus dan November. Untuk pasar perak ditemukan bahwa bulan September merupakan satu-satunya bulan yang mampu menghasilkan return positif tertinggi yang signifikan, bulan lainnya tidak berdampak terhadap return perak. Pasar platinum ternyata memiliki pola yang berbeda dengan pasar emas dan perak. Pada pasar platinum ditemukan bahwa bulan Januari, Februari dan Agustus merupakan bulan yang mampu menghasilkan return positif yang signifikan pada produk platinum. Bulan Januari merupakan bulan yang menghasilkan return terbesar untuk produk platinum, disusul bulan Februari dan Agustus. Sama halnya dengan pasar platinum, pasar paladium ternyata juga dipengaruhi oleh bulan Januari yang 
merupakan bulan return terbesar. Hal ini menunjukkan bahwa January effect berlaku untuk pasar platinum dan paladium. Pasar paladium tidak hanya dipengaruhi oleh bulan Januari saja, melainkan juga dipengaruhi oleh bulan Maret dan Juni, dengan bulan Juni sebagai bulan yang menghasilkan return negatif yang signifikan. Sedangkan pasar minyak mentah WTI hanya dipengaruhi oleh bulan Maret secara positif.

\section{SIMPULAN, KETERBATASAN DAN IMPLIKASI}

\section{Simpulan}

Penelitian ini menyimpulkan bahwa terdapat month of the year effect pada pasar modal Indonesia, Malaysia, Filipina, Thailand dan Singapura. Bahkan month of the year effect juga terjadi pada pasar komoditas untuk produk emas, perak, platinum dan paladium. Hal ini menunjukkan bahwa pasar modal dan pasar komoditas ini cenderung tidak efisien dalam bentuk lemah. Bahkan return sebagian pasar modal dan pasar komoditas yang diteliti juga ternyata dipengaruhi oleh volatilitas masa lalu masing-masing pasar modal dan pasar komoditas.

January effect terjadi untuk pasar modal Filipina dan pasar modal Singapura. January effect juga terjadi untuk pasar platinum dan paladium. Hanya pasar platinum yang mengalami February effect. March effect terjadi pada pasar modal Indonesia dan pasar paladium serta pasar minyak mentah WTI, sedangkan April effect hanya terjadi di pasar modal Indonesia. May effect terjadi di pasar modal Singapura, namun dengan efek negatif yang menyebabkan terjadinya return negatif. June effect memiliki dampak yang berbeda untuk pasar modal Singapura dan pasar paladium. June effect berdampak positif pada pasar modal Singapura dan berdampak negatif pada pasar paladium. July effect terjadi di pasar Singapura saja dan membukukan return terbesar untuk pasar modal Singapura. August effect hanya terjadi di pasar emas dan pasar platinum. Sedangkan September effect terjadi di pasar modal Singapura, pasar emas dan pasar perak. Khusus untuk pasar emas dan perak, September effect ini memberikan dampak positif yang besar sehingga menyebabkan return emas dan return perak di bulan September merupakan yang terbesar dibandingkan bulan-bulan lainnya. October effect hanya berlaku untuk pasar modal Malaysia saja. Demikian pula November effect juga hanya berlaku untuk pasar emas. Sementara itu December effect muncul di pasar modal Indonesia, pasar modal Malaysia, pasar modal Thailand dan pasar modal Singapura dengan dampak yang positif.

\section{Keterbatasan}

Penelitian ini hanya menggunakan periode penelitian yang ada secara umum, belum melakukan pemisahan antara periode-periode penelitian yang berpotensi mengandung suatu efek gejolak di pasar modal seperti krisis finansial global di tahun 
2008. Kesimpulan dalam penelitian ini hanya berlaku umum dan dapat kurang sesuai dengan temuan yang secara khusus mengkaji periode ketika terjadi krisis, dimana faktor eksternal dan nonteknikal lebih dominan pada pasar modal dan pasar komoditas pada periode-periode tersebut. Oleh sebab itu penelitian mendatang disarankan juga mempertimbangkan adanya pemisahan antara periode normal dengan periode krisis dalam penelitian yang mengkaji topik yang sama.

\section{Implikasi}

Hasil penelitian ini menunjukkan bahwa perilaku masing-masing pasar modal dan pasar komoditas ini cenderung berbeda sehingga kondisi ini dapat menimbulkan peluang untuk strategi switching bagi para investor yang memiliki pengetahuan dan akses di antar pasar modal dan pasar komoditas. Investor dapat secara aktif melakukan active switching pada pasar modal dan pasar komoditas. Pada saat ditemukan return yang negatif di bulan tertentu pada suatu pasar modal atau komoditas, investor lebih baik memindahkan portofolionya kepada pasar saham yang membukukan return positif pada suatu pasar modal atau komoditas tertentu sehingga tetap dapat membukukan return yang positif pada portofolionya sepanjang tahun.

\section{DAFTAR PUSTAKA}

Bollerslev, T. 1986. Generalized autoregressive conditional heteroscedasticity. Journal of Econometrics. No.31: 307-327.

Boudreaux, D. O. 1995. The monthly effect in international stock markets: Evidence and implications. Journal Of Financial And Strategic Decisions. Vol.8 No.1: 15-20.

Brockman, P., dan D. Michayluk. 1998. Individual versus institutional investors and the weekend effect. Journal of Economics and Finance. Vol.22 No.1: 71-85.

Chia, R. C. Y., dan V. K. S. Liew. 2012. Month-of-the-year and symmetrical effects in the Nikkei 225. IOSR Journal of Business and Management. Vol.3 No.2: 68-72.

Debasish, S. S. 2012. An empirical study on month of the year effect in gas, oil and refineries sectors in Indian stock market. International Journal of Management and Strategy. Vol.3 No.5: 1-16.

Enders, W. 2009. Applied Econometric Time Series. John Wiley \& Sons, Inc.

Fama, E. F. 1965. The behavior of stock-market prices. Journal of Business. Vol.38 No.1: 34-105.

1970. Efficient capital markets: A review of theory and empirical work. Journal of Finance. Vol.25 No.2: 383-417. 
- 1998. Market efficiency, long-term returns, and behavioral finance. Journal of Financial Economics. Vol.49: 283-306.

Georgantopoulos, A. G., D. F. Kenourgios, dan A. D. Tsamis. 2011. Calendar anomalies in emerging balkan equity markets. International Economics \& Finance Journal. Vol.6 No.1: 67-82.

Giovanis, E. 2009. Month-of-the-year effect: Evidence from GARCH models in Fifty five stock markets. MPRA Paper (22328).

Greene, W. H. 2003. Econometric Analysis 5th Edition. New Jersey: Prentice Hall.

Fatta-Bahadur, K. C., dan N. K. Joshi. 2005. The Nepalese stock market: efficient and calendar anomalies. Economic Review: Occasional Paper of Nepal Rastra Bank. No.17: 40-85.

Kamath, R. R., R. Chakornpipat, dan A. Chatrath. 1998. Return distributions and the day-of-the-week effects in the stock exchange of Thailand. Journal of Economics and Finance. Vol.22 No.2: 97-106.

Lakonishok, J., dan E. Maberly. 1990. The weekend effect: trading pattern of individual and institutional investors. Journal of Finance. Vol.45 No.1: 231224.

Marrett, G., dan A. Worthington. 2011. The month-of-the-year effect in the australian stock market: a short technical note on the market, industry and firm size impacts. Australasian Accounting Business and Finance. Vol.5 No.1: 117-123.

Nawaz, S., dan N. Mirza. 2012. Calendar anomalies and stock returns: a literature survey. Journal of Basic and Applied Scientific Research. Vol.2 No.12: 23212329.

Olowe, R. A. 2010. Oil price volatility, global financial crisis and the month-of-theyear effect. International Journal of Business and Management. Vol.5 No.11: 156-170.

Pearce, D. K. 1996. The robustness of calendar anomalies in daily stock returns. Journal of Economics and Finance. Vol.20 No.3: 69-80.

Schwert, G. W. 2002. Calendar anomalies and market efficiency. NBER Working Paper. No.9277.

Sias, R. W., dan L. T. Starks. 1995. The day-of-the-week anomaly: the role of institutional investors. Financial Analysts Journal. (May/June): 58-67.

Silva, P. M. 2010. Calendar "anomalies" in the Portuguese stock market. Investment Analysts Journal. Vol.71: 37-50.

Swami, R. 2012. Calendar anomalies in the bourses of South Asia. Market Convergence. Vol.2 No.2: 64-74. 
Wang, Y. J., dan M. M. Walker. 2000. An empirical test of individual and institutional trading patterns in patterns in Japan, Hong Kong, and Taiwan. Journal of Economics and Finance. Vol.24 No.2: 178-194. 